\title{
Clinical Performance Monitoring in Undergraduate Dental Education - Paper-Based vs. Online Logbooks; Reporting by Students vs. Reporting by Instructors
}

\author{
Fatin Abdulrahman Hasanain ${ }^{1}$, Hanin Essam Yeslam²
}

1, 2 Department of Restorative Dentistry, King Abdulaziz University, Jeddah, Saudi Arabia.

\section{ABSTRACT}

\section{BACKGROUND}

Medical and dental education is highly dependent on the development of students' clinical skills in addition to their theoretical knowledge. The use of logbooks to monitor the clinical procedures performed by students provides a great advantage in the educational process. Because of the pandemic, utilisation of digital logbooks may prove to be more advantageous. This study aims to investigate the effective use of online progress records and as to whether they actually decrease the chance of error compared to the traditional paper-based logbooks.

\section{METHODS}

In this quasi-experimental study, 139 student logbooks were studied to compare online and paper-based clinical procedures. Logbook monitoring of undergraduate dental students reported by the students themselves vs. instructors was compared. Students filled mandatory individual paper-based logbooks, reporting the number of clinical procedures performed in that year. Additionally, they filled online log- sheets, and updated them regularly. Instructors proofread and signed the paper-based students' logbooks. Instructors also separately submitted individual online forms recording each student's clinical procedure performed in clinical sessions. A total of 556 logbook records was collected. The mean number of procedures recorded by the students and instructors (online and paper-based) were statistically compared.

\section{RESULTS}

The mean number of procedures recorded in student-reported online logbooks were significantly lower than that in all other logbooks. Paper-based and online instructorreported logbook data was identical to that of student reported paper-based logbooks.

\section{CONCLUSIONS}

Within the scope of the study, it was concluded that online tools are an asset and may be used as a substitute for paper-based monitoring of clinical activity for instructors. However, students' compliance updating and uploading online forms is a factor, which is a matter of concern.

\section{KEY WORDS}

Undergraduate Dental Logbooks, Clinical Progress Records, Monitoring Methods, Monitoring Tools, Undergraduate Dental Monitoring, Undergraduate Clinical Procedures Records
Corresponding Author: Dr. Fatin Hasanain, King Abdulaziz University, Al Jame'a Dist. - Al Jame'a St. P.O. Box 31600, Jeddah 21418. Saudi Arabia

E-mail: fhasanain@kau.edu.sa

DOI: $10.14260 / \mathrm{jemds} / 2021 / 314$

How to Cite This Article:

Hasanain FA, Yeslam HE. Clinical performance monitoring in undergraduate dental education - paper - based vs. online logbooks reported by students vs. instructors. J Evolution Med Dent Sci 2021;10(20):1501-1505, DOI: 10.14260/jemds/2021/314

Submission 12-11-2020, Peer Review 10-03-2021, Acceptance 19-03-2021, Published 17-05-2021.

Copyright (C) 2021 Fatin Abdulrahman Hasanain et al. This is an open access article distributed under Creative Commons Attribution License [Attribution 4.0 International (CC BY 4.0)] 


\section{BACKGROUND}

Medical and dental education are currently moving towards a competence-based system rather than being mainly focused on theoretical knowledge.1,2 Dental education is highly dependent on developing certain critical competencies and honing the skills of the students to achieve a higher standard of care for the patients being treated.

The use of printed booklets and logbooks to document the clinical procedures performed by the students is considered a helpful tool to assess the clinical competencies progress that was achieved by the students during the academic year. Logbooks are commonly used in the postgraduate level in both medical and dental education to document the clinical skills acquired prior to the certification exams. The use of printed logbooks has been widespread at the undergraduate levels as well. $^{3-5}$ In an undergraduate restorative dentistry course, all the student-logbooks had to be collected periodically in order to monitor and calculate the clinical procedural credits gained. ${ }^{6}$ Despite their usefulness, formulating and perfecting these logbooks in addition to maintaining accuracy of scores could prove to be a challenge.2,5 The frequent collection of logbooks to complete interim progress reports is inefficient and time consuming due to the large number of required clinical procedures and their respective procedural credits that must be recorded, collated and tabulated. ${ }^{6}$ To decrease the inevitable human error (s) that would take place during the formulation of interim progress reports, multiple instructors often review the results. This verification step further prolongs an already time-consuming process. During the current Covid-19 pandemic, collection of paper-based records from students is even more complicated due to the necessary infection control precautions required at this time.

To overcome above mentioned difficulties, online forms were created to monitor dental procedures performed by undergraduate dental students and automate the creation of interim and final progress reports. Both instructors and students filled the online forms in addition to the paper-based logbooks. This study aims to investigate the utilisation of online progress records and whether they actually decrease the chance of error compared to the traditional paper-based logbooks.

\section{METHODS}

This quasi experimental study was approved by the KAU ethical committee with the protocol number $61-12$ - 19. The duration of the study was 9 months, from Sept 2018 to May 2019. Traditionally, first year clinical undergraduate dental students were required to record their completed clinical procedures in pre-approved paper-based logbooks which were countersigned by instructors. The logbooks were then physically collected at specific times during the year by the operative dentistry course director (OpDen $\mathrm{CD}$ ) to collate and tabulate the clinical progress and create interim records of the students taking that course.

The OpDen CD team developed two online forms / sheets to help automate the process of interim data collection and student assessment -

1. An online tabular Google-Sheets for students to selfreport their clinical progress. To maximise compliance and the sheet's ease of use, the students were only asked to electronically self-report the number of restorative dental procedures completed on a weekly basis in the respective table cell next to their names. The students were required to finalise the updated Google-Sheets by the end of the academic year.

2. A custom made online form using Google-Forms for the course instructors to fill during each restorative dental session. The form consisted of a multiple-choice question (MCQ) and answer based recording format (Figure 1). The instructors filled in each question on the sheet for every clinical procedure completed by each student.

Access to the output of the forms as well as editing privileges were limited to the OpDen CD team only.

A total of 556 log-sheets were studied as shown in Figure 2. They were divided into 4 groups as follows; Group IO for the instructor-reported online log-sheets, Group IP for the instructor-reported paper-based log-sheets, Group SO for the student-reported online log-sheets, Group SP for the studentreported paper-based log-sheets $(\mathrm{N}=139)$. The data in groups IO, IP and SP were identical. Hence the analysis will be between SP and SO only.

The results were analysed statistically using the computer program Statistical Package for the Social Sciences (SPSS) v.23. Paired t test was used to compare between group SP and SO.

\begin{tabular}{|c|c|c|}
\hline \multicolumn{3}{|l|}{ RESULTS } \\
\hline Difference between Groups SO and SP & Frequency & Percent \\
\hline The same & 70 & 50.4 \\
\hline 1 & 37 & 26.6 \\
\hline 2 & 9 & 6.5 \\
\hline 3 & 3 & 2.2 \\
\hline 4 & 2 & 1.4 \\
\hline 5 & 2 & 1.4 \\
\hline 6 & 2 & 1.4 \\
\hline 8 & 2 & 1.4 \\
\hline 9 & 2 & 1.4 \\
\hline 10 & 1 & .7 \\
\hline 13 & 2 & 1.4 \\
\hline 14 & 3 & 2.2 \\
\hline 15 & 1 & .7 \\
\hline 17 & 2 & 1.4 \\
\hline 18 & 1 & .7 \\
\hline Total & 139 & 100.0 \\
\hline \multicolumn{3}{|c|}{$\begin{array}{c}\text { Table 1. Comparison of Total Procedures } \\
\text { between Groups SO and SP }\end{array}$} \\
\hline
\end{tabular}




\section{${ }^{*}$ Required \\ 1. Academic Week ${ }^{8}$ \\ Mark only one oval \\ $\bigcirc$ Week 1 \\ Week 2 \\ 2. Which clinical session?* \\ Mark only one oval \\ First day session \\ second day session}

Clinical Procedures Evaluation Form

\section{Student's Name (in alphabetical order) * \\ Mark only one oval \\ $\bigcirc$ First student \\ Second student}

4. Students Attendance

Mark only one oval

Absent

swapped

\section{Student's performed clinical requirement ${ }^{*}$ Mark only one oval \\ clinical requirement 1 \\ clinical requirement 2}

6. Quality Evaluation Criteria for Clinical Requirement Mark only one oval per row

\begin{tabular}{lllll} 
& NA & 0 & 1 & 2 \\
\hline Criteria 1 & & 0 & 0 & 0 \\
\hline Criteria 2 & & 0 & 0 & 00
\end{tabular}

\section{Feedback}

Figure 1. An Overview of the Online Google Form Utilised by the Instructors to Record the Clinical Procedures Performed by the Students during the Clinical Sessions

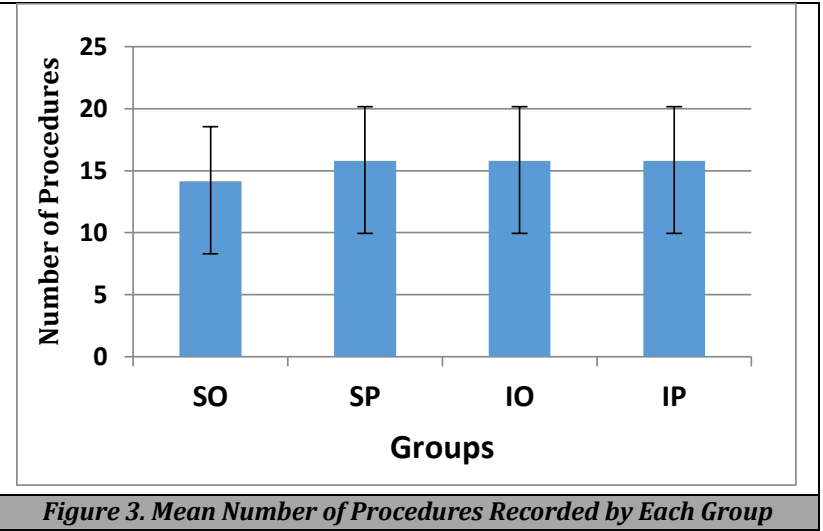

This quasi-experimental study compared the mean number of procedures recorded by first year clinical undergraduate operative dentistry students and their clinical instructors in both the paper-based vs. online logbooks (Figure 3). The null hypothesis stated that there is no significant difference in the mean number of total procedures recorded online vs. on paper whether reported by instructors or the students.

The data in groups IO, IP and SP were identical. Hence the analysis was done between groups SP and SO only. Table 1 shows the differences in number of procedures logged. Paired t-test showed a significant difference between the two groups as shown in Table 2. Interestingly, $50.4 \%$ of the students had logged the same number of procedures online and on paper. $26.6 \%$ of the students had a discrepancy of only 1 procedure, while $6.5 \%$ had a difference of 2 procedures. Thus, $83.5 \%$ of the students logged a difference of 2 or less procedures in the online vs. paper forms. Therefore, the authors rejected the null-hypothesis.

\section{DISCUSSION}

In 1997, the Dearing Report recommended the use of a progress file for all students in higher education. ${ }^{7-9}$ The purpose of such files was mainly to provide an "official record of achievement".

Recording of the dental procedures in student logbooks adds structure and focus to the learning process as it allows regular monitoring of the clinical performance of undergraduate dental students in the specified course. ${ }^{10}$ This is especially relevant in dental education as there is an emphasis on mastering certain critical competencies and their clinical application in various dental disciplines during supervised clinical sessions.

Allowing students to participate in their own learning experience by taking responsibility and personalising their own learning progress is beneficial in the overall learning experience. ${ }^{5,11}$ Millennials or digital natives, as described by Marc Prensky in 2001, are the students of the current generation, who prefer to use electronic technology to meet their educational needs. ${ }^{12,13}$ These students might even be more technologically competent than their instructors and educators, which could pose a challenge. ${ }^{14}$ In order to accommodate this generation of students, dental educational tools should ideally include innovative electronic tools that would captivate the students' attention and motivate them in their learning journey. In this study, the OpDen CD team increased the involvement of the students in their own learning experience by incorporating technological tools that included an online Google Sheet as well as the traditional paper-based logbooks, in which the students had to record and sign their own clinical achievements by their instructors. The use of the electronic Google Sheet by the students allowed them to monitor their own clinical progress continually. This was similar to the electronic record books employed by Bookhan et al. in $2016^{6}$ and electronic portfolios and logbooks discussed in other studies. 4,15,16 This self-monitoring approach can have a positive influence on the student's behaviour; motivating them to realise their full potential, acquiring required clinical competencies, and eventually providing better patient's care. ${ }^{17,18}$

Traditionally, paper-based logbooks submitted by the students were the only method of monitoring available. However, it was both inconvenient and inefficient for the OpDen CD team as it required the physical collection of the logbooks from all the students taking the course at different intervals during the academic year. The recorded procedures were then tabulated and recorded for each student. 


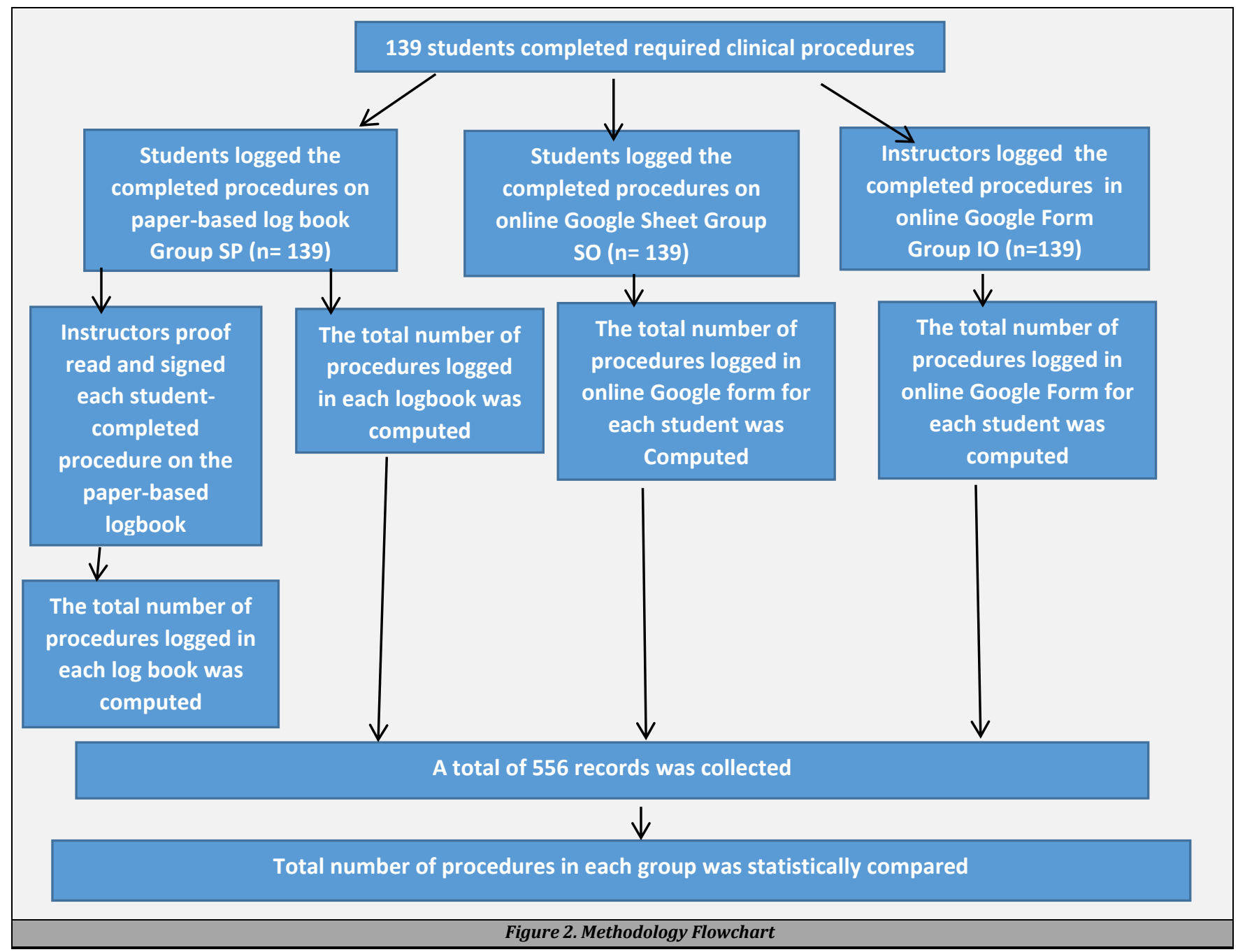

To assure accuracy, the collation had to be proofread by more than one faculty member in the team, which doubled the time required to finalise interim progress reports for the students. This prolonged process could adversely affect the educational experience of the students performing below class average and potentially delay any necessary support for students who need it in the form of clinical guidance and practical exercises to improve their learning outcome. ${ }^{6}$

Electronic monitoring systems have several obvious benefits over paper-based ones. These include ease and speed of data collection, manipulation, customisation, as well as the ease of sharing or transferring information as required. Another benefit of digital forms, especially during the Covid19 pandemic, was the resultant decrease in the number of items, which were handled by multiple individuals. This would eventually lessen the chances of inadvertent crosscontamination. The use of Google Forms by the instructors in the current study to report the clinical procedures performed by each student during the weekly clinical sessions allowed continuous monitoring of the students' progress, work, and effective attendance on a weekly basis. This was also affirmed in a previous study, where electronic student record books were found to be more efficient in monitoring both students' performance and attendance in a specific course. ${ }^{6}$

Maintaining accuracy of the data entered by either students or instructors is a challenge when evaluating tools for monitoring student's clinical procedure progress records. Accuracy of such records is highly important in dental and medical education as it shows the students' progress in core clinical competencies. ${ }^{19,20}$ In the current study, the mean number of total procedures recorded in the students' selfreported paper-based logbooks was not significantly different than instructor-reported logbooks. This could be explained by the fact that the paper-based logbooks had to be continually proofed and signed by their instructors, which added more supervision to the whole process.

However, the mean number of total procedures performed recorded online by the students was significantly lower than that in all other logbook records. This decrease in number could be attributed to the lack of students' motivation to update their information online in the presence of other forms of monitoring methods. This shows that the accuracy of online student self-reported logbooks still depends on the students' compliance and sense of responsibility in regards to their educational needs. Thus, their quality should not be assumed, as the students might have not spent adequate time filing and updating their own electronic records ${ }^{11}$ An increase in the instructors' motivation of the students to update the forms might help with the accuracy of such reports. Another proposed reason for the discrepancy between the students' online and paper-based numbers could be the fact that some students may not be willing to showcase their academic and clinical performance to their colleagues. These students may either be the underachievers or those who are well ahead of the rest of their peers. Thus, increasing the confidentiality of student self-reported online logbooks can possibly help 
improve their compliance and hopefully achieve a more comparable result to the instructor-reported logbooks. It would, however, decrease the student's ability to self-monitor in comparison to his / her peers.

\section{CONCLUSIONS}

Within the limitations of this study, it can be concluded that online student monitoring by supervisors is a viable and an equally comparable alternative to paper-based monitoring. However, students' compliance and sense of responsibility still plays a role in the accuracy of their online logbook records. Thus, students' self-reporting does in fact benefit from instructors' review and guidance. Additionally, improving the confidentiality of the online logbooks by using the students ID numbers rather than their names could help increase the accuracy of students' self-reported online records.

Data sharing statement provided by the authors is available with the full text of this article at jemds.com.

Financial or other competing interests: None.

Disclosure forms provided by the authors are available with the full text of this article at jemds.com.

\section{REFERENCES}

[1] Jenkins L, Mash B, Derese A. The national portfolio for postgraduate family medicine training in South Africa: a descriptive study of acceptability, educational impact and usefulness for assessment. BMC Med Educ 2013;13:101.

[2] Gadbury-Amyot CC, Bray KK, Austin KJ. Fifteen years of portfolio assessment of dental hygiene student competency: lessons learned. J Dent Hyg 2014;88(5):26774.

[3] Donato AA, George DL. A blueprint for implementation of a structured portfolio in an internal medicine residency. Acad Med 2012;87(2):185-91.

[4] Fida NM, Hassanien M, Shamim MS, et al. Students perception of portfolio as a learning tool at King Abdulaziz University Medical School. Med Teach 2018;40(Suppl 1):S104-13.

[5] Marambe KN. Portfolio: an innovative teaching, learning and assessment tool in medical training. Sri Lanka Journal of Medicine 2015;24(1):25-9.

[6] Bookhan V, de Wet FA, Brandt PD. Comparison of a custom made electronic record book database with a traditional student record book for recording clinical procedural credits and continuous clinical assessments in Restorative Dentistry. South African Dental Journal 2016;71(3):119-24.

[7] Nierenberg D, Eliassen MS, McAllister SB, et al. A webbased system for students to document their experiences within six core competency domains during all clinical clerkships. Acad Med 2007;82(1):51-73.

[8] Remuzzi G, Schieppati A. Dearing - a report to be embraced. Lancet 1997;350(9074):308.

[9] Vernazza C, Durham J, Ellis J, et al. Introduction of an eportfolio in clinical dentistry: staff and student views. Eur J Dent Educ 2011;15(1):36-41.

[10] The Dearing Report. The National Committee of Inquiry into Higher Education. Higher Education in the learning society. Main Report. London: Her Majesty's Stationery Office 1997.

[11] Thomson PJ, Boyle CA. Auditing clinical teaching in oral surgery: the use of a student log book. Dent update 1996;23(7):283-6.

[12] Buckley S, Coleman J, Davison I, et al. The educational effects of portfolios on undergraduate student learning: a Best Evidence Medical Education (BEME) systematic review. Med Teach 2009;31(4):282-98.

[13] Prensky M. Digital natives, digital immigrants. On the Horizon 2001;9(5):1-6.

[14] Kennedy GE, Judd TS, Churchward A, et al. First year students experiences with technology: are they really digital natives? Australasian Journal of Educational Technology 2008;24(1).

[15] de Wet C, Yelland M. The challenges and opportunities in medical education for digital natives and immigrants in Scotland and Abroad. Scott Med J 2015;60(4):152-4.

[16] Schuttpelz-Brauns K, Narciss E, Schneyinck C, et al. Twelve tips for successfully implementing logbooks in clinical training. Med Teach 2016;38(6):564-9.

[17] Joshi MK, Gupta P, Singh T. Portfolio-based learning and assessment. Indian Pediatr 2015;52(3):231-5.

[18] Kirkup ML, Adams BN, Meadows ML, et al. Development and implementation of an electronic clinical formative assessment: dental faculty and student perspectives. J Dent Educ 2016;80(6):652-61.

[19] Atkinson JC, Zeller GG, Shah C. Electronic patient records for dental school clinics: more than paperless systems. Journal of Dental Education 2002;66(5):634-42.

[20] Dosumu EB, Dosumu 00, Lawal FB. Quality of records keeping by undergraduate dental students in Ibadan, Nigeria. Ann Ib Postgrad Med 2012;10(1):13-7. 